University of Nebraska - Lincoln

DigitalCommons@University of Nebraska - Lincoln

Biological Systems Engineering: Papers and

Publications

Biological Systems Engineering

2022

\title{
Resistome and mobilome in surface runoff from manured soil as affected by setback distance
}

\author{
Noelle Mware \\ University of Nebraska - Lincoln, nmware@huskers.unl.edu \\ Maria C. Hall \\ University of Nebraska-Lincoln \\ Selvakumar Rajendran \\ University of Nebraska-Lincoln \\ John E. Gilley \\ USDA-ARS, john.gilley@ars.usda.gov \\ Amy Schmidt \\ University of Nebraska-Lincoln, aschmidt@unl.edu
}

See next page for additional authors

Follow this and additional works at: https://digitalcommons.unl.edu/biosysengfacpub

Part of the Bioresource and Agricultural Engineering Commons, Environmental Engineering Commons, and the Other Civil and Environmental Engineering Commons

Mware, Noelle; Hall, Maria C.; Rajendran, Selvakumar; Gilley, John E.; Schmidt, Amy; Bartelt-Hunt, Shannon; Zhang, Yifan; and $\mathrm{Li}, \mathrm{Xu}$, "Resistome and mobilome in surface runoff from manured soil as affected by setback distance" (2022). Biological Systems Engineering: Papers and Publications. 784.

https://digitalcommons.unl.edu/biosysengfacpub/784

This Article is brought to you for free and open access by the Biological Systems Engineering at DigitalCommons@University of Nebraska - Lincoln. It has been accepted for inclusion in Biological Systems Engineering: Papers and Publications by an authorized administrator of DigitalCommons@University of Nebraska Lincoln. 


\section{Authors}

Noelle Mware, Maria C. Hall, Selvakumar Rajendran, John E. Gilley, Amy Schmidt, Shannon Bartelt-Hunt, Yifan Zhang, and Xu Li 


\title{
Resistome and mobilome in surface runoff from manured soil as affected by setback distance
}

\author{
Noelle A. Mware $^{\text {a, }}$ Maria C. Hall ${ }^{\text {a }}$, Selvakumar Rajendran ${ }^{\mathrm{a}, \mathrm{b}}$, John E. Gilley ${ }^{\mathrm{c}}$,

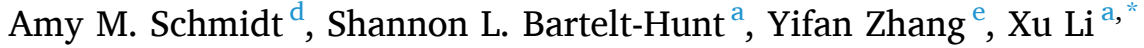 \\ ${ }^{a}$ Department of Civil and Environmental Engineering, University of Nebraska-Lincoln, USA \\ ${ }^{\mathrm{b}}$ Department of Nanobiotechnology, PSG Institute of Advanced Studies, Tamil Nadu, India \\ ${ }^{\mathrm{c}}$ Agricultural Research Service, United States Department of Agriculture, USA \\ d Department of Biological Systems Engineering, University of Nebraska-Lincoln, USA \\ ${ }^{\mathrm{e}}$ Department of Nutrition and Food Science, Wayne State University, USA
}

\section{H I G H L I G H T S}

- Manure land application increased the antibiotic resistance genes (ARGs) in runoff.

- A setback of $40 \mathrm{~m}$ is needed to reduce the total ARGs in runoff to background levels.

- Manure application has little impact on the resistome of soil in the setback region.

- Soil-borne ARGs replaced manure-borne ARGs as setback distance increased.

\section{A R T I C L E I N F O}

Editor: Dr. G. Jianhua

\section{Keywords:}

Swine manure

Soil

Runoff

Resistome

Setback distance
G R A P H I C A L A B S T R A C T

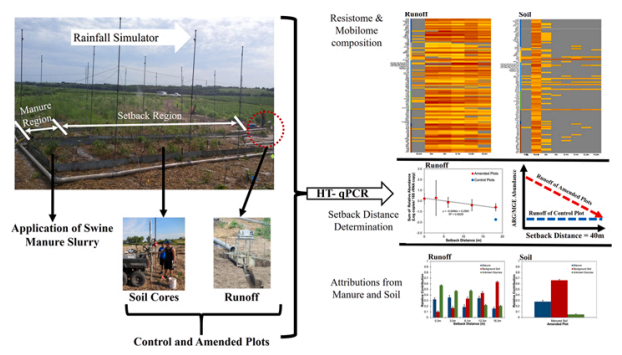

\section{A B S T R A C T}

Land application of livestock manure introduces antibiotic resistance genes (ARGs) and mobile genetic elements (MGEs) into the soil environment. The objectives of this study were to examine the changes of resistome and mobilome in runoff and soil as a function of setback distance, i.e., the distance between manured soil and surface water, and to quantify the contributions of manure and background soil to the ARGs and MGEs in surface runoff. The resistome and mobilome in runoff and soil from a field-scale plot study were characterized using a high throughput quantitative polymerase chain reaction (HT-qPCR) array. It was estimated that a setback distance of $\sim 40 \mathrm{~m}$ is required to reduce the total abundance of ARGs and MGEs in runoff from amended plots to that in control runoff. The resistome and mobilome of the soil in the setback region was not affected by manure-borne ARGs and MGEs. SourceTracker analyses revealed that background soil gradually became the predominant source of the ARGs and MGEs in runoff as setback distance increased. The results demonstrate how manure-borne ARGs and MGEs dissipated in agricultural runoff with increasing setback distance and had limited impacts on the resistome and mobilome of soil within the setback region.

\footnotetext{
* Correspondence to: 900 N 16th Street, NH W150D, Lincoln, NE 68588-0531, USA.

E-mail address: xuli@unl.edu (X. Li).
} 


\section{Introduction}

Land application of swine manure can improve soil quality and crop productivity by providing nutrients and organic matter. However, land application can also introduce manure-borne antibiotic resistance to the soil environment. Several studies have reported increased levels of antibiotic resistance genes (ARGs) and mobile genetic elements (MGEs) in soil, groundwater, and surface water within agricultural areas receiving livestock manure (Holger Heuer, 2011; Su et al., 2014; Zhu et al., 2017). Proper manure management practices are required to prevent manure-borne contaminants from reaching water bodies. Various manure management strategies have been examined for their effectiveness in reducing the load of ARGs to surface water through runoff, for example, manure land application method (Joy et al., 2013), land application timing (Barrios et al., 2020), and the use of vegetative buffers (Soni et al., 2015).

Setback distance, the minimum distance required between an area where manure is land applied and an outlet to a water source or a residential/commercial area, has also been recommended as a best management practice (BMP) to control manure-borne contaminants, such as nutrients and fecal bacteria, in the environment (Oun et al., 2014). For example, Pennsylvania recommends a setback distance of at least $100 \mathrm{ft}$ $(30.5 \mathrm{~m})$ from surface waters for manure application (Pennsylvania Department of Environmental Protection, 2011). Previous studies have evaluated setback distance requirements for manure constituents such as nutrients (Al-wadaey et al., 2010), antibiotic resistant fecal indicators (Meyers et al., 2020), as well as antibiotics and ARGs (Hall et al., 2020). In the study by Hall and colleagues, quantitative polymerase chain reaction (qPCR) was used to quantify eight ARGs and one MGE in runoff from test plots with varying setback distances. While qPCR is a reliable way to quantify individual ARGs, the number of ARGs tested in a single study is often limited. In comparison, high throughput quantitative polymerase chain reaction (HT-qPCR) can serve as a powerful tool to assess the overall resistome in environmental samples. HT-qPCR has been employed to characterize resistomes in various environments, including soil amended with sewage sludge (Xie et al., 2018a), soil and manure in swine farms (Zhu et al., 2013), soil amended with swine manure slurry (Chen et al., 2017), urban soil irrigated with reclaimed water (Wang et al., 2014), and agricultural soil (Hu et al., 2017). The application of HT-qPCR could provide a comprehensive assessment about the impacts of setback distances on the resistome and mobilome of runoff and soil following the land application of manure.

In addition to revealing the composition of resistome, HT-qPCR data may also be used to quantify the relative contributions of environmental sources to the resistome of an environmental sink. While land applied manure contains ARGs and MGEs that are of animal origins, background soil is a reservoir of naturally occurring ARGs and MGEs (Durso et al., 2016). As runoff flows away from regions receiving manure, the contributions of manure-borne vs. soil-borne ARGs/MGEs are expected to gradually change. SourceTracker was developed as a Bayesian approach to estimate the relative contribution of sources to the contamination in a sink (Knights et al., 2011). SourceTracker has been previously used to quantify the relative contributions of individual environmental sources to the microbiome and resistome in a sink environment (Baral et al., 2018a; Baral et al., 2018b). SourceTracker analysis has high accuracy, specificity, and sensitivity in source identification (Henry et al., 2016). A double-blinded study yielded a $91 \%$ accuracy in identifying and attributing the sources of fecal contamination in ambient freshwater samples based on $16 \mathrm{~S}$ rRNA gene amplicon sequencing (Staley et al., 2018). Analyzing HT-qPCR data in SourceTracker has the potential to quantify the relative contributions of various environmental sources to the resistome in runoff and soil following the land application of livestock manure.

The objectives of this study were to examine the changes of resistome and mobilome in surface runoff and soil as a function of setback distance and to quantify the contributions of manure and background soil to the
ARGs and MGEs in runoff and soil within the setback region (i.e., the region downslope from the soil receiving manure). Swine manure slurry was applied to field plots containing a designated manure region on the upslope portion of a plot and a setback region with various setback distances (i.e., $0 \mathrm{~m}$ to $18.3 \mathrm{~m}$ ) downslope from the manure region. Rainfall simulation tests were conducted on the field plots. HT-qPCR was employed to characterize the resistome and mobilome of runoff samples collected at the bottom of setback regions as well as soil in the manure region and soil within the setback region. The study was intended to expand a common manure management strategy, setback distance, for the control of manure borne ARGs and MGEs. The program SourceTracker was used to determine the relative contributions of manure and background soil to the ARGs and MGEs in runoff and soil. This study generated quantitative information that can be used to develop guidelines on setback distances for mitigating the environmental impacts of manure-borne ARGs and MGEs in agricultural runoff.

\section{Materials And methods}

\subsection{Study area}

The study was conducted at the University of Nebraska - Lincoln Rogers Memorial Farm located $18 \mathrm{~km}$ east of Lincoln, NE, during summer 2016. The area had a slope of $4.9 \%$. The $\mathrm{pH}$ and the conductivity of the soil were 6.7 and $0.51 \mathrm{dS} \mathrm{m}^{-1}$, respectively. The soil type in the study area was Aksarben silty clay loam (fine, smectite, mesic Typic Argiudoll) constituting of $22 \%$ sand, $44 \%$ silt, and $34 \%$ clay. No manure had been applied to the study area since 1966 . Winter wheat had been harvested in the summer of 2015 and glyphosate had been applied after harvest for weed control. The soil surface was covered with winter wheat residues at the time of the field experiment.

\subsection{Field experiment setup}

The setup of the field experiment has been described previously (Hall et al., 2020). In brief, the study site was divided into 20 plots and the experiment was set up as a randomized complete block design with a total of four blocks. Within each block of five plots, five setback distances of $0.0 \mathrm{~m}, 3.0 \mathrm{~m}, 6.1 \mathrm{~m}, 12.2 \mathrm{~m}$, and $18.3 \mathrm{~m}$ (i.e., 0, 10, 20, 40, and $60 \mathrm{ft}$, respectively) were randomly assigned to the plots (Fig. 1). All plots were $3.7 \mathrm{~m}$ wide and the length varied for setback distances. At the upslope section of each plot, a $3.7 \mathrm{~m}$ by $4.9 \mathrm{~m}$ area was designated as the manure application region and received swine manure slurry. The setback distance was measured from the bottom of the manure region. At the bottom of each plot was a metal collection unit that discharged into a flume where flow was measured by a stage recorder. Rainfall was simulated using a portable sprinkler system established to cover the entire plot area (i.e., both the manure region and the setback region) to

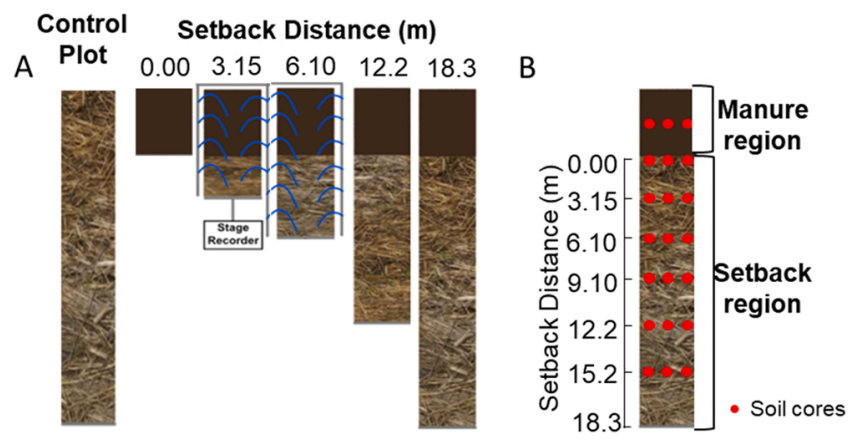

Fig. 1. Field setup and sampling design. Runoff samples were collected at the end of each plot with varied setback distances (A). Soil cores were collected at the center of the manure region and at varied setback distances in the setback region of the $18.3 \mathrm{~m}$ plot (B). 
produce a relatively uniform rainfall. The intensity of the rainfall was approximately $52 \mathrm{~mm} \mathrm{hr}^{-1}$ and was recorded by rain gages placed along the outside perimeter of the plots. Water was extracted from an onsite irrigation well. When the flow reached a steady state condition, grab samples of surface runoff were collected in 1-L sterile plastic bottles for microbial analyses. Samples were stored on ice and transported back to the laboratory for analyses.

\subsection{Collection of Runoff and Soil Samples}

The field experiment was scheduled over a 10-week period with two plots established and tested each week. Swine manure slurry was collected from a commercial swine operation facility in southeast Nebraska. The chemical and physical properties of the manure were characterized at the Ward Laboratory (Grand Island, NE) and reported in Table S1. Based on its nitrogen content, the liquid slurry was surface broadcast at a rate required to meet the annual nitrogen requirements for corn (i.e., $151 \mathrm{~kg} \mathrm{~N} \mathrm{ha}^{-1}$ year $^{-1}$ for an expected yield of $9.4 \mathrm{Mg} \mathrm{ha}^{-1}$, a reasonable yield goal for the soil, cropping, management, and climate conditions for this area). Rainfall simulation tests were first conducted on the pair of plots on Monday and Tuesday to determine the constituent concentrations in control runoff (i.e., surface runoff from plots prior to manure application). On Wednesday, swine manure slurry was collected and broadcast by hand onto the manure region of the two plots. On Thursday, rainfall simulation took place on the plots and runoff was collected at the end of each plot (i.e., the end of the setback region). On Friday, the same procedure as Thursday was repeated. Plots with the longest setback distance (i.e., $18.3 \mathrm{~m}$ ) were used to generate controls for runoff (i.e., surface runoff from the plots prior to manure application) and for soil (i.e., soil from the plots prior to manure application and any rainfall simulation).

Soil core samples of $30 \mathrm{~cm}$ depth were collected from the plots with the longest setback distance (i.e., $18.3 \mathrm{~m}$ ) five days after the last rainfall simulation (i.e., the Wednesday of the following week). Three replicate soil cores were collected at the center of the manure region and at $0.0 \mathrm{~m}$, $3.0 \mathrm{~m}, 6.1 \mathrm{~m}, 9.1 \mathrm{~m}, 12.2$, and $15.2 \mathrm{~m}$ within the setback region. Surface soil samples $(0-10 \mathrm{~cm})$ in replicate soil cores from the same downslope distance were pooled to form one composite sample for further analysis. Soil cores were also obtained from an adjoining plot area where manure had not been applied to serve as a control.

\subsection{DNA extraction}

Manure, soil and runoff samples were stored at $-20^{\circ} \mathrm{C}$ until DNA extraction. Runoff samples were filtered through $0.22-\mu \mathrm{m}$ filters (Millipore, Billerica, MA). DNA was extracted from these filters (i.e., runoff samples) as well as manure and soil samples using the DNeasy PowerLyzer PowerSoil DNA Isolation kit (Qiagen Inc, Germantown, MD) and purified using the ZYMO OneStep ${ }^{\text {TM }}$ PCR Inhibitor Removal Kit (Irvine, CA), according to manufacturers' instructions. Extracted DNA was concentrated to obtain a final concentration of $>15 \mathrm{ng} / \mu \mathrm{L}$ for each sample, following the protocol of the DNA isolation kit. The quality and concentration of DNA were assessed using an Invitrogen Qubit Flourometer (Life Technology, Grand Island, NY).

Extracted DNA was sent to Michigan State University's Genomic Core for HT-qPCR analyses using the Wafergen SmartChip Real-time PCR system (WaferGen Biosystems, Inc, Fremont, CA) to determine the diversity and abundance of ARGs and MGEs in the samples. Prior to analyzing the samples, a preliminary test was run on the representative manure, soil, and runoff samples to determine the ARGs and MGEs that were relevant to these samples. From the preliminary test, an HT-qPCR array consisting of 144 primer sets, including 143 primer sets that target dominant classes of ARGs and MGEs (i.e., defined as resistome and mobilome, respectively) and one primer set that targets the $16 \mathrm{~S}$ rRNA gene (Table S1), was assembled for our samples (Stedtfeld et al., 2018). All HT-qPCR reactions were performed in three technical replicates.

\subsection{Data analysis}

A threshold cycle cutoff $\left(\mathrm{C}_{\mathrm{T}}\right)$ of 28 was used in data analysis (Stedtfeld et al., 2018). For the initial data processing, the gene copy number (GCN) of the $16 \mathrm{~S}$ rRNA gene and ARGs/MGEs was estimated from their $\mathrm{C}_{\mathrm{T}}$ values with a threshold cycle cutoff of 28 as the detection limit. The relative abundance (RA) of ARGs/MGEs with respect to the $16 \mathrm{~S}$ rRNA gene was calculated using the following equations:

$$
\begin{aligned}
& G C N=10^{\left(28-C_{T}\right)} /\left(\frac{10}{3}\right) \\
& \Delta C_{T}=C_{T, \mathrm{ARG} / \mathrm{MGE}}-C_{T, 16 \mathrm{~S}} \\
& R A_{\mathrm{ARG} / \mathrm{MGE}}=2^{\left(\Delta C_{T}\right)} \\
& S R A=\Sigma \quad R A_{\mathrm{ARG} / \mathrm{MGE}, i}
\end{aligned}
$$

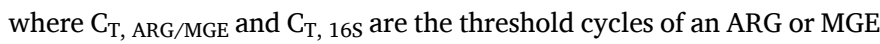
and the $16 \mathrm{~S}$ rRNA gene, respectively; $\mathrm{RA}_{\mathrm{ARG} / \mathrm{MGE}}$ is the relative abundance of an ARG or MGE, expressed as the copies of ARG or MGE per copy of the $16 \mathrm{~S}$ rRNA gene; SRA is the sum of the relative abundance of all ARGs and MGEs in a sample; $\mathrm{RA}_{\mathrm{ARG}}$ /MGE subclass is the relative abundance of ARG or MGE belonging to a subclass.

Gene copy number and relative abundance was calculated using Microsoft Excel 2016. Heatmap graphs were produced in $\mathrm{R}$ using the ggplot2 package (Wickham, 2016). Spearman correlation $(\rho)$ was performed using the psych package version 1.7.8 in R (Revelle, 2017). Strong correlations, defined as $\rho>0.8$ and $p<0.01$, among ARGs and MGEs were utilized to construct the co-occurrence networks for manure, runoff, and soil samples. The Frucherman Reingold layout was used to visualize the network topology on the open-source interactive platform Gephi v.0.9.2 (Bastian et al., 2009). Principal coordinate analysis (PCoA) plots was conducted using the vegan package in $\mathrm{R}$ to visualize the Bray-Curtis dissimilarity among the different sample types (Oksanen et al., 2019). Adonis test was conducted in $\mathrm{R}$ using the vegan package to determine the significance of the differences in resistome and microbiomes in the samples.

To estimate the relative contributions of manure and background soil to the resistome and mobilome in runoff and soil, SourceTracker analysis was conducted (Knights et al., 2011). GCN data were used to generate an ARG/MGE data table. Five independent runs were conducted using default settings to reduce the effect of false prediction. At least two biological replicates of each sample type were included in each individual analysis. A mapping file was generated from the ARG/MGE data table where samples were defined as either source or sink according to conceptual models. The SourceTracker output showed the proportional contribution of each source to the designated sink sample. The relative contribution is the average of the proportion contributions for each source from five independent simulations.

\section{Results}

\subsection{Composition of resistome and mobilome in surface runoff}

Manure application had significant impacts on the composition of resistome and mobilome in surface runoff. As shown in the heat map in Fig. 2A, compared to the control runoff, the runoff from manure amended plots contained ARGs and MGEs with higher diversity and abundance. Furthermore, as the setback distance increased, the diversity and the abundance of ARGs/MGEs decreased (Fig. 2A). Specifically, the ARGs detected conferred resistance to several classes of antibiotics: aminoglycoside, beta lactam, macrolide-lincosamide-streptogramin B (MLSB), sulfonamide, and tetracycline, as wells as multidrug resistance (MDR) and other antibiotics (e.g., amphenicol, quinolone, streptomycin, and vancomycin). The MGEs included primarily transposase (e.g., 

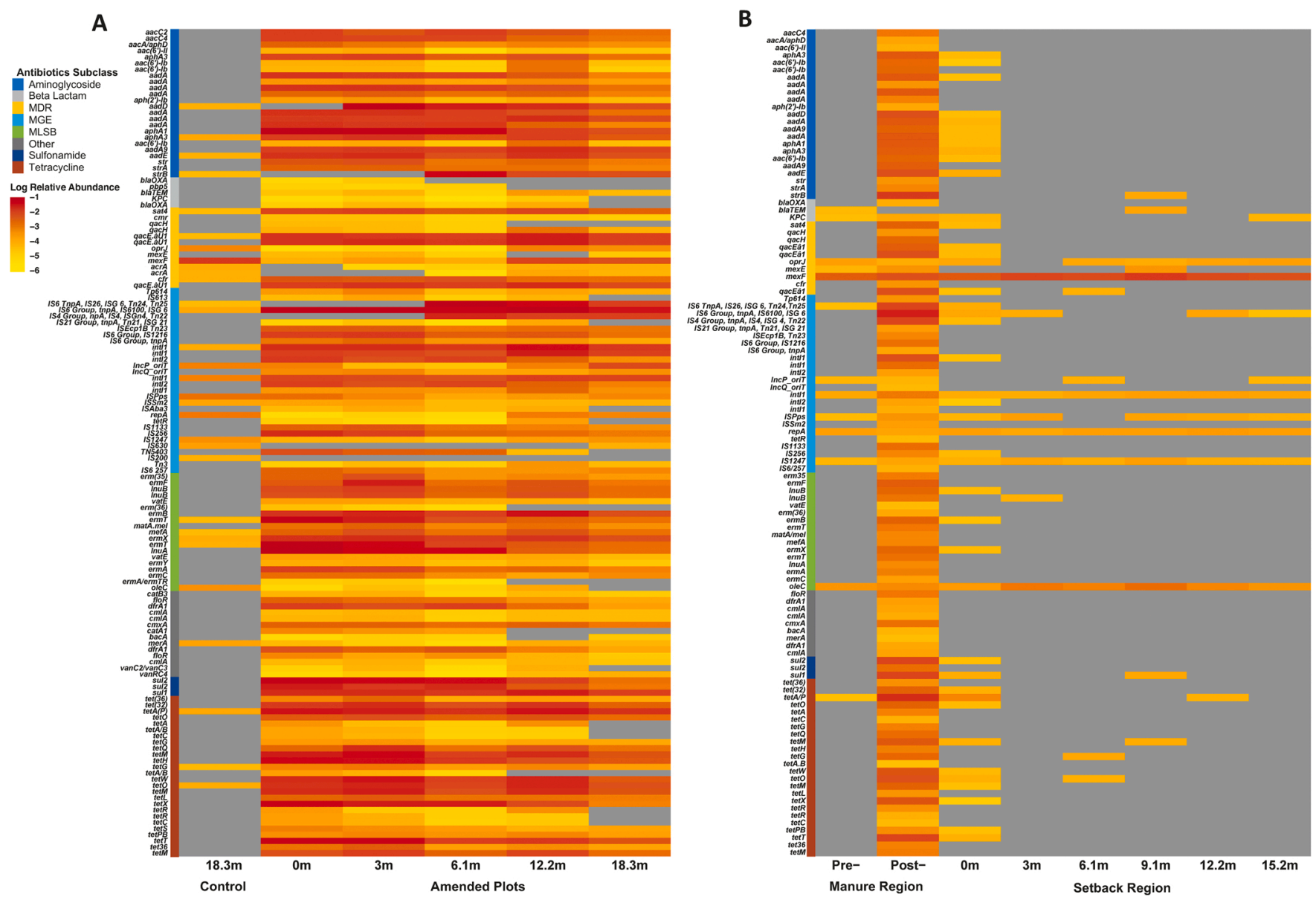

Fig. 2. Relative abundance of ARGs and MGEs in runoff samples from control plots collected at $18.3 \mathrm{~m}$ as well as in runoff samples from manure amended plots with various setback distances (A); and in soil before and after manure application and across the setback distances at $0 \mathrm{~m}, 3 \mathrm{~m}, 6.1 \mathrm{~m}, 9.1 \mathrm{~m}, 12.2 \mathrm{~m}$ and $15.2 \mathrm{~m}$ (B). The columns represent different sample type, and the rows represent relative abundance for specific ARGs or MGEs. MDR, multidrug resistance; MLSB, MacrolideLincosamide-Streptogramin B; and MGE, mobile genetic elements. The grey bars show ARG/MGE was not detected in the sample.

Tp614), insertion sequences (e.g., IS6, IS1247 and ISSm2), plasmid incompatibility groups (e.g., IncP_oriT), and integrase (e.g., intI1). For the resistome in runoff from the amended plots, the percentage of ARGs conferring resistance to aminoglycoside and MLSB decreased as setback distance increased, while the percentage of MDR increased (Fig. 3A). The main classes of genes detected in the runoff from the control plots were ARGs belonging to MDR (67.19\%) and MGEs (29.45\%, Fig. 3A).

\subsection{Composition of Resistome and Mobilome in Soil}

Manure application significantly altered the resistome and mobilome of the soil in the manure region, but not on the soil in setback region, of the amended plots. As shown in Fig. 2B, the application of manure significantly increased the diversity and abundance of ARGs and MGEs in soil (i.e., pre- vs. post-manure application) with Adonis test $p$-value of 0.001 . Specifically, in the soil prior to manure application, ARGs belonging to MDR were the most abundant with a contribution of 86.36\% (Fig. 3B). After manure application, ARGs belonging to MDR dropped to $10.12 \%$ for soil in the manure region of amended plots, while the ARGs conferring resistance to aminoglycoside (29.74\%) and tetracycline $(23.01 \%)$, as well as MGE $(21.17 \%)$, became the major types. The impacts of manure application on the soil resistome and mobilome quickly diminished as the setback distance increased. Resistome composition of soil at the $0.0 \mathrm{~m}$ setback distance consisted of major genes classes conferring resistance to MDR (73.27\%), aminoglycoside (3.83\%), and tetracycline (6.95\%). The composition of the resistome in the soil at subsequent setback distances was similar to that of the original soil resistome (Fig. 3B). Genes that occurred consistently among all soil samples were mexF, repA, oleC, intI1, and IS1247, which represent multidrug resistance gene, MLSB resistance gene, class I integron integrase, and insertion sequence, respectively (Fig. 2B).

\subsection{Sum of Relative Abundance of ARGs and MGEs}

The sum of relative abundance (SRA) of ARGs and MGEs in runoff decreased with increasing setback distance. SRA, calculated as the sum of the relative abundance (i.e., normalized to the $16 \mathrm{~S}$ rRNA gene) of all ARGs and MGEs detected in the HT-qPCR array, serves as a quantitative measure of the level of resistome and mobilome in samples. The SRA of ARGs and MGEs in control runoff was - $1.70 \log$ copy per $16 \mathrm{~S}$ rRNA gene copy at the $18.3 \mathrm{~m}$ setback distance (Fig. 4A). The SRA of genes in runoff from the amended plots decreased from $0.20 \log$ copy per $16 \mathrm{~S}$ rRNA gene copy at $0 \mathrm{~m}$ setback distance to $-0.60 \log$ copy per $16 \mathrm{~S}$ rRNA gene copy at $18.3 \mathrm{~m}$ setback distance. A linear trend line described the trend of the SRA values as a function of setback distance relatively well $\left(\mathrm{R}^{2}=0.9229\right.$, Fig. $\left.4 \mathrm{~A}\right)$. According to this trend line, it was estimated that a setback distance of $40.5 \mathrm{~m}$ is needed to reduce the SRA of ARGs and MGEs in the runoff from the manure amended plots to that of the runoff occurring within the control area.

Application of swine manure slurry significantly increased the SRA of ARGs and MGEs in soil within the manure region, but not those in soil within the setback region, of the amended plots. The average SRA of ARGs and MGEs in the soil of the control plots was - 2.40 log copy per $16 \mathrm{~S}$ rRNA gene copy, while the average SRA increased substantially to 

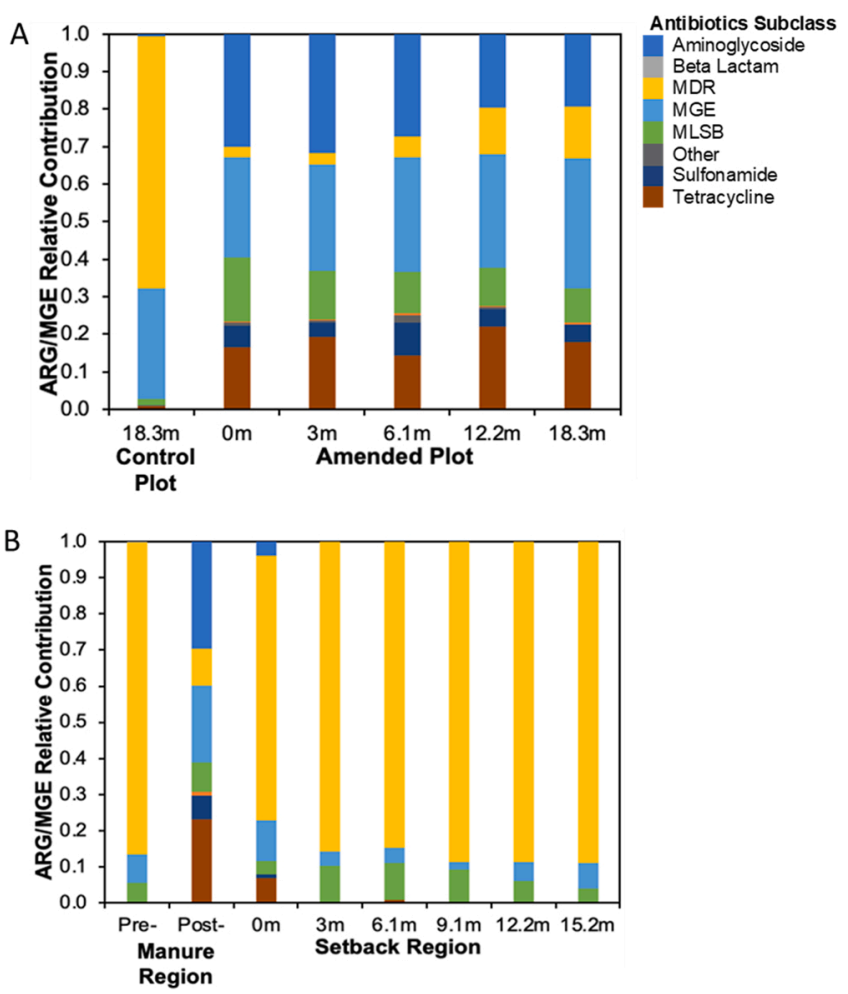

Fig. 3. The composition of resistome in runoff samples (A) and in soil samples (B). The runoff samples were from control plots at the distance of $18.3 \mathrm{~m}$ and from amended plots with various setback distance. The soil samples were from manure region before and after manure application and in setback region with setback distances of $0 \mathrm{~m}, 3 \mathrm{~m}, 6.1 \mathrm{~m}, 9.1 \mathrm{~m}, 12.2 \mathrm{~m}$ and $15.2 \mathrm{~m}$. MDR, multidrug resistance; MLSB, Macrolide-Lincosamide-Streptogramin B; and MGE, mobile genetic elements.

- 0.57 log copy per $16 \mathrm{~S}$ rRNA gene copy in the soil of the manure region of amended plots (Fig. 5B). The average SRA of ARGs and MGEs in soil within the setback region of the amended plots remained low, between -2.22 to $-1.82 \log$ copy per $16 \mathrm{~S}$ rRNA gene copy, suggesting little impacts from the manure applied to the manure region.

\subsection{Beta-Diversity Among Sample Types}

Beta diversity analyses on resistome and mobilome in manure, runoff, and soil samples confirm the trends observed in the earlier

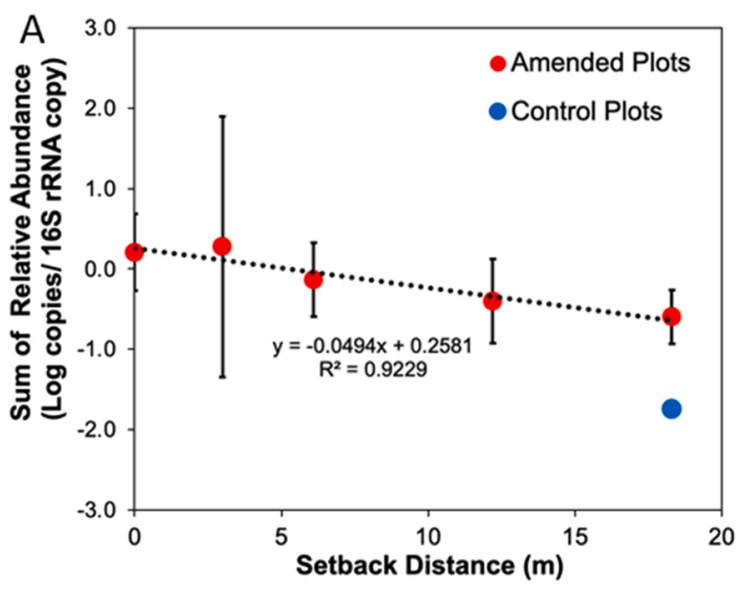

analyses. The two principal components captured $63 \%$ and $14 \%$ of the total variations of resistome and mobilome among sample types (Fig. 5). The manure samples are clustered together and are separated from the other types of samples. Runoff samples collected from the amended plots were clustered together (Adonis test, $\mathrm{p}=0.587$ ) and separated from the runoff samples collected from the control plots (Adonis test, $\mathrm{p}=0.001$ ). The soil from the setback region of the amended plots were clustered together along with the original soil (i.e., soil from control plots, Adonis test, $\mathrm{p}=0.120$ ). There was also a significant difference between soil samples from the manure region and soil samples from the setback region (Adonis test, $\mathrm{p}=0.010$ ), whereas the soils from various setback distances were clustered together (Adonis test, $\mathrm{p}=0.506$ ).

\subsection{Attribution to the ARGs and MGEs in the Surface Runoff from the Amended Plots}

To determine the relative contributions of various environmental sources to the ARGs and MGEs in runoff and soil samples, two conceptual models were established (Fig. 6). In the two conceptual models, runoff from amended plots and soil in manure region were defined as the environmental sinks of ARGs and MGEs, while manure and background soil were defined as the environmental sources.

The relative contribution of swine manure slurry to the ARGs and

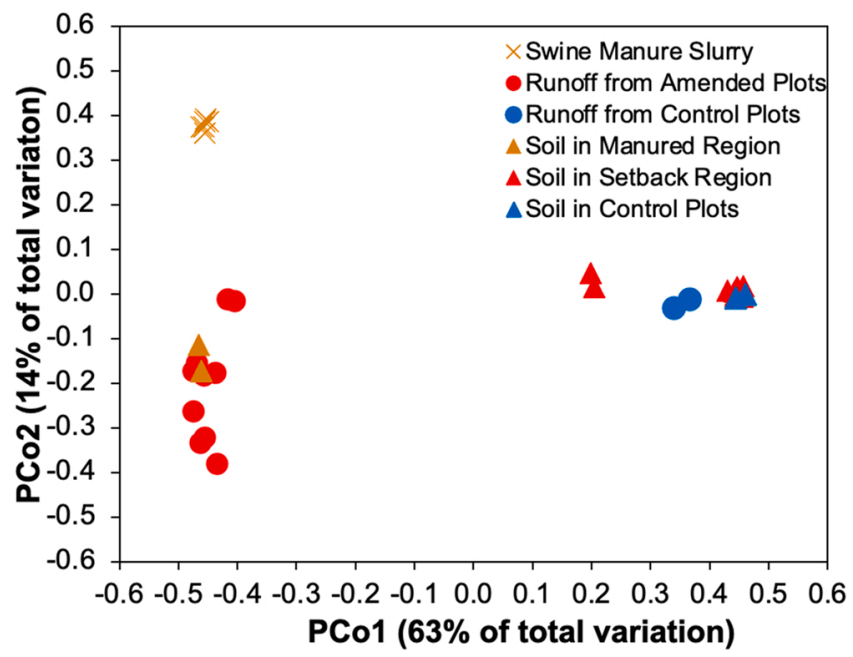

Fig. 5. Principle coordinate analysis (PCoA) plot for manure, runoff and soil samples based on the Bray-Curtis distance matrices showing the overall distribution pattern of ARGs and MGEs.

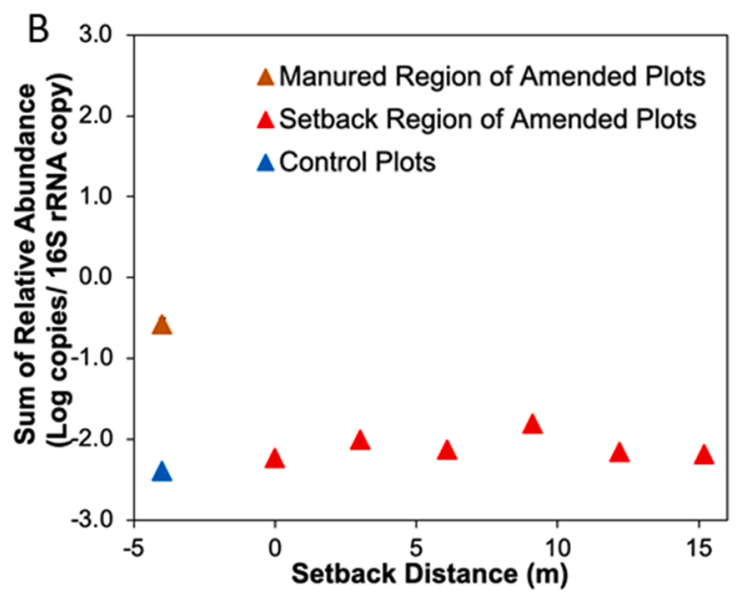

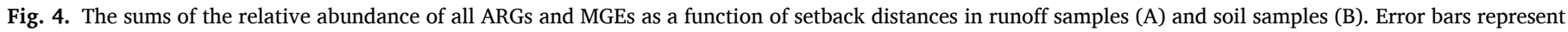
standard deviations from 4 replicate plots. The error bars for the soil samples in Panel B are too small to be visible in the plot. 
A

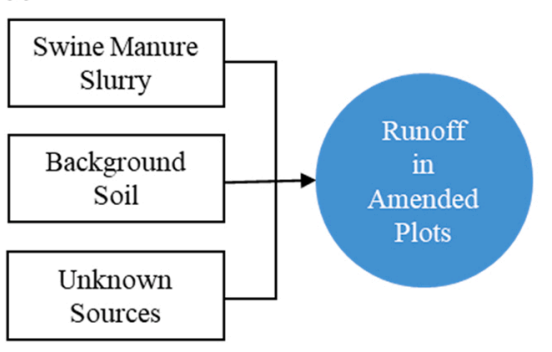

B

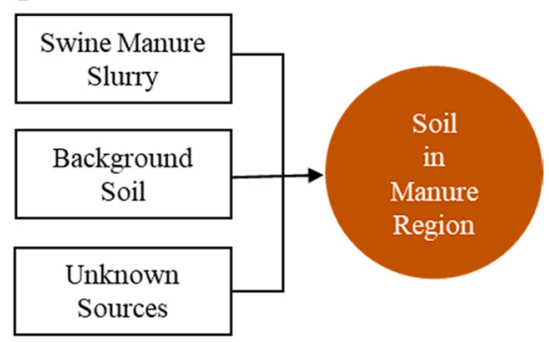

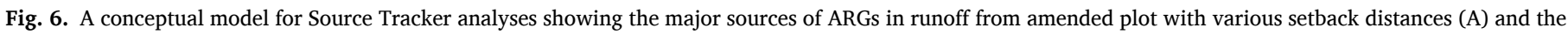
soil from the manure region (B).

MGEs in runoff decreased substantially from $32.4 \%$ and $16.0 \%$, as the setback distance increased from $0-18.3 \mathrm{~m}$ (Fig. 7A). The relative contribution of background soil to the ARGs and MGEs in the runoff increased from $10.2 \%$ at the $0 \mathrm{~m}$ setback distance to $63.4 \%$ at the $18.3 \mathrm{~m}$ setback distance. As the contribution of soil increased with setback distance, the contribution of unknown sources decreased (Fig. 7A). For the soil samples collected within the manure region, background soil was the largest contributor (66.2\%) of the ARGs and MGEs in manured soil (Fig. 7B), while manure contributed $28.9 \%$.

\subsection{Co-Occurrence between ARGs and MGEs}

The co-occurrence patterns between ARGs and MGEs in different sample types was also investigated. In general, the co-occurrence of tetracycline resistance genes and integron MGEs exhibited strong correlations (Spearman's correlation coefficient $\rho>0.8$ and $p<0.01$ ) for manure, soil in setback region, and runoff from amended plots (Fig. 8). The co-occurrence patterns were established in the ARGs-MGEs networks. The numbers of nodes, edges and modularity indices for each sample type are summarized in Table 1 . The Gephi platform was used to partition the network into different modules depending on their modularity class. The modularity indices obtained were 0.894 for swine manure slurry, 0.364 for runoff, and 0.645 for soil samples in the setback region (Table 1 ), indicating the presence of a modular structure (Newman, 2006).

The network analyses also identified individual ARGs and MGEs that were highly correlated with others. In the runoff samples (Fig. 8B), insertion sequences IS613 and ISEcp1 and transposase Tp614 were highly correlated with multiple ARGs conferring resistance to tetracyclines, MLSB, and aminoglycosides. The co-occurrence pattern was parsed to four major modules exhibiting dense connections in runoff samples at various setback distances. Modules represent clusters of

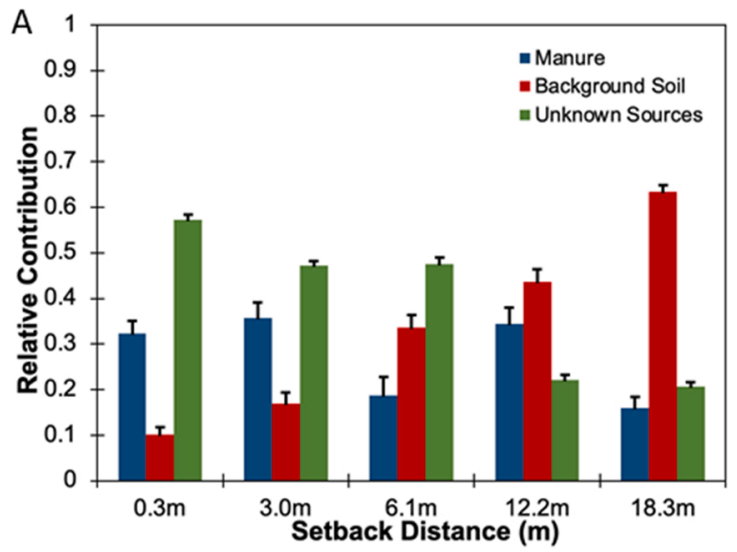

nodes that interact more among themselves than with other nodes (Li et al., 2015). In particular, the IS1133, tetPB, ermX and intI1 genes were the most well-connected ARGs and MGEs within modules I, II, III and IV, respectively, and may be used as indicators for the co-occurring ARGs and MGEs in each module. The soil network exhibited five distinct modules with intI2, aad $\mathrm{D}$ and tet $\mathrm{W}$ being the most well-connected genes at the center of the clusters Modules I, II and III, respectively. Overall, compared to soil and manure samples, runoff samples from various setback distances exhibited a larger hub with more dense connections.

\section{Discussion}

\subsection{Effects of setback distance on ARGs and MGEs in runoff}

In this investigation, HT-qPCR was employed to examine the effects of setback distance on the composition and source of resistome and mobilome in runoff and soil. In a companion study, we employed qPCR to quantify eight ARGs and one MGE in runoff and soil samples as a function of increasing setback distance (Hall et al., 2020). In that study, we demonstrated that a range of $36-58 \mathrm{~m}$ were needed to lower the ARGs and MGE concentrations in runoff from amended plots to their respective concentrations in control runoff. In this study, a setback distance of $40.5 \mathrm{~m}$ was determined on the basis of the SRA of ARGs and MGEs. By using two different molecular methods, qPCR and HT-qPCR, we reached similar conclusions on the setback distance needed to reduce ARG and MGE concentrations in runoff to background levels.

Dilution is believed to be the principal mechanism in reducing the relative abundance of ARGs and MGEs in runoff as setback distance increased. Previous studies have investigated the transport of fecal indicator bacteria such as E.coli in runoff, where dilution was primarily responsible for a decrease in the concentration of fecal coliform with distance from the source of manure (Roodsari et al., 2005). In another

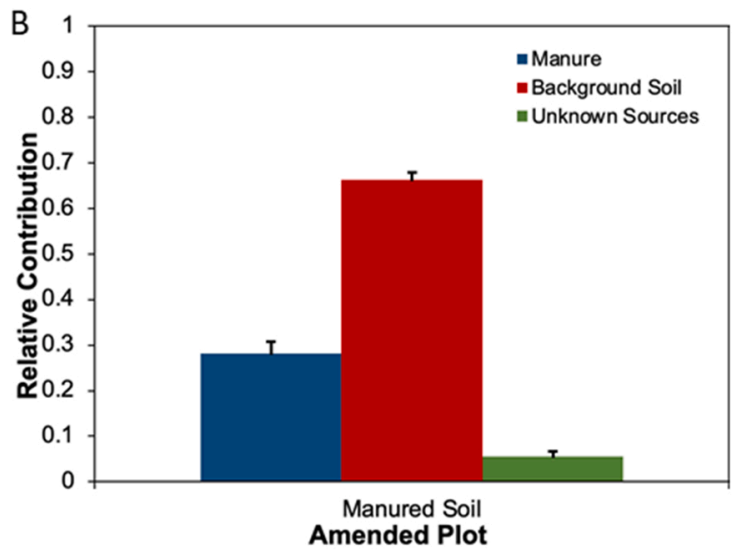

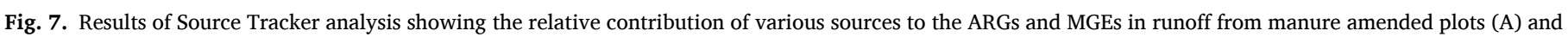

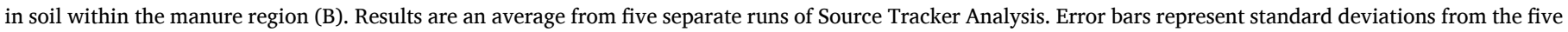
separate runs. 
(A)

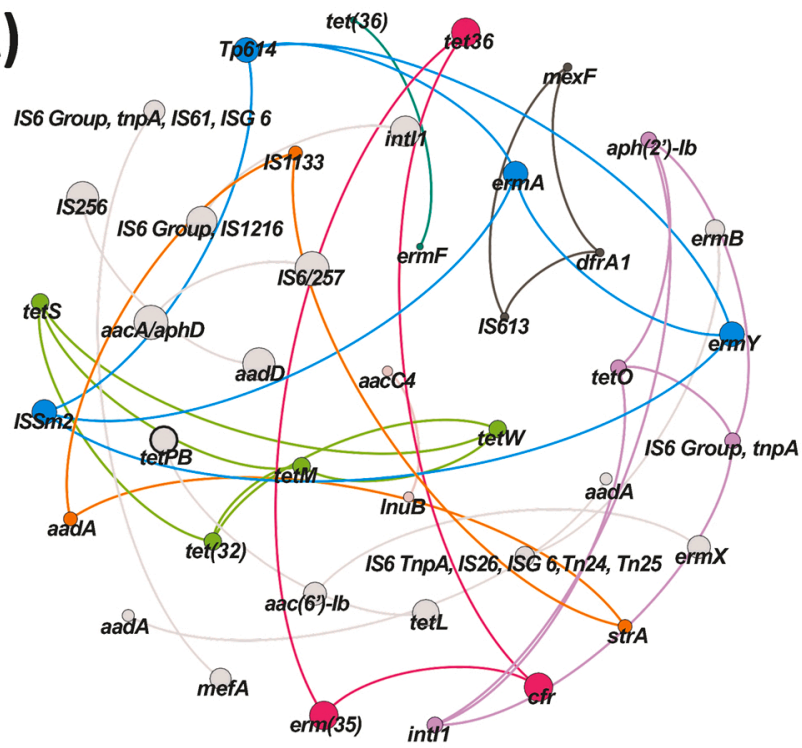

(C)

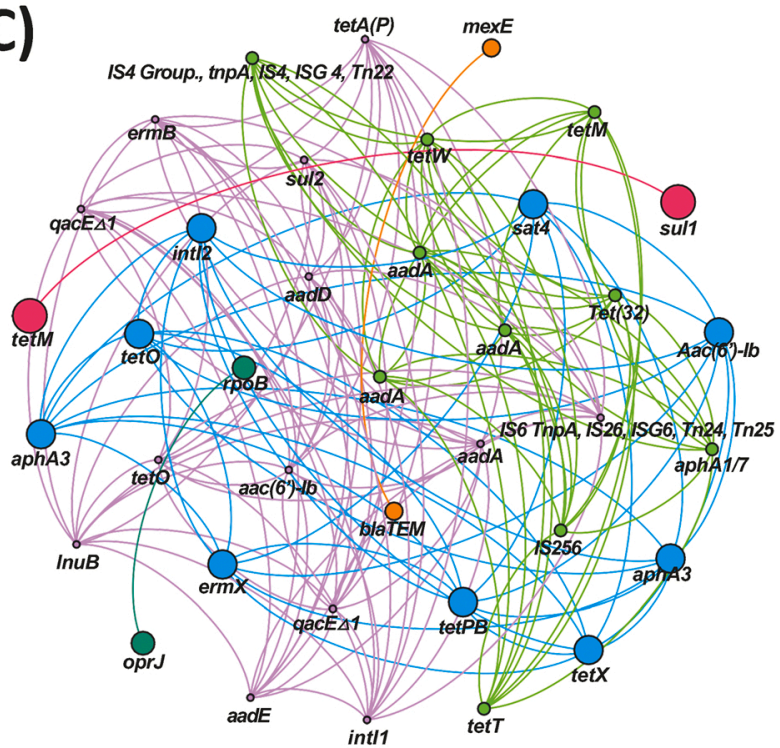

(B)

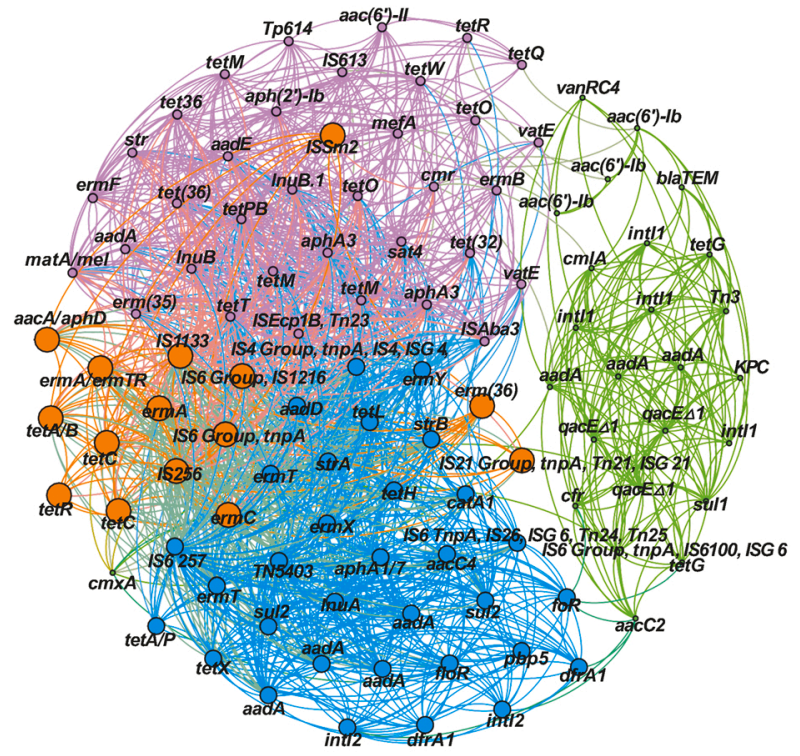

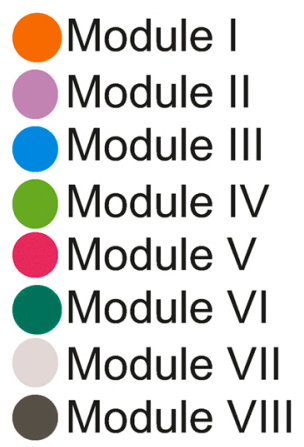

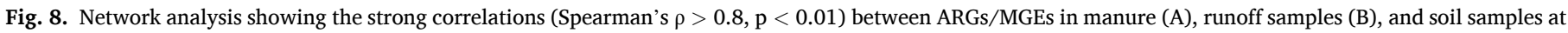
varied setback distances (C). The size of the nodes is proportional to the number of significant correlations between ARGs/MGEs.

Table 1

Number of nodes and edges for each sample type as well as the modularity index.

\begin{tabular}{lcrl}
\hline Sample Type & Nodes & Edges & Modularity index \\
\hline Swine manure slurry & 41 & 37 & 0.894 \\
Runoff from amended plots & 123 & 1629 & 0.364 \\
Soil in setback regions & 38 & 160 & 0.645 \\
\hline
\end{tabular}

study, dilution was attributed to be one of the causes that led to the attenuation of ARGs in a receiving river system downstream from a cattle holding pond and a wastewater treatment plant (Pruden et al., 2012). In this study, the dilution of manure particles in runoff facilitated the reduction of the relative abundance of ARGs and MGEs in runoff as setback distance increased.

The settling of manure particles could also attribute to the reduction of the relative abundance of ARGs and MGEs in runoff as setback distance increased. As the manure particles settled from runoff, the relative abundance of ARGs and MGEs could decrease in runoff (Jacobs et al., 2019). In this study, the soil surface of the experimental plots was covered with wheat residues that might have caused reduction in particle transport in runoff. The presence of crop residue cover may reduce runoff velocity and increase infiltration (Mei et al., 2018; Zhao et al., 2020). Reduction in the runoff velocity may lead to more settling of particles from runoff (Ginting et al., 1998; Grande et al., 2005). A previous study showed decrease in particle loads with increase in field length due to particle settling (Mailapalli et al., 2013). Reduced runoff velocity could facilitate the settling of manure borne ARGs and MGEs, leading to a reduced relative abundances of ARGs and MGEs in runoff as setback distances increased.

Distinguishing the anthropogenic vs. natural sources of resistome and mobilome in an environment is important in assessing the risk of ARGs and MGEs of the environment. There is a lack of quantitative information on the relative contributions of manure-borne vs. soil-borne ARGs and MGEs in runoff. A key finding revealed by SourceTracker 
analyses was that background soil gradually became the main source of the ARGs and MGEs in the runoff as setback distance increased. Application of manure can increase the abundance and diversity of ARGs and MGEs in soil (Li et al., 2017; Zhang et al., 2017), as shown by the results from the manure region in this study. However, the land application of manure had limited impacts on the soil downslope from the manure application area. Microbes in the surface soil of the setback region can be washed off into runoff, making soil the chief contributor of resistome and mobilome in overland flow.

According to the SourceTracker analyses in Fig. 7A, one or more sources of the ARGs and MGEs in runoff were not accounted for in our conceptual model (Fig. 6). The unknown source(s) were particularly significant for runoff discharged from plots with shorter setback distances. We speculate that the unknown sources could be the crop residues that covered the entire test plots in this study. There have not been extensive research on the ARGs and MGEs associated with crop residues. A previous study detected antibiotic resistant bacteria in nearly half of the corn stalk residue samples collected throughout the state of Nebraska (Staley et al., 2020). Hence, it is plausible to expect the occurrence of ARGs and MGEs on the crop resides in the plots of this study. Another possible explanation could be associated with the depth of the soil cores that were sampled. In this study, we composited the top $10 \mathrm{~cm}$ of the soil cores to represent topsoil. In the rainfall simulation tests, it is likely that only the top few centimeters of the surface soil were washed off by runoff. The "dilution" of the resistome and mobilome of top soil by soils at greater depths might have caused the SourceTracker model to attribute the ARGs and MGEs in runoff to unknown sources.

\subsection{Effects of Setback Distance on ARGs and MGEs in Soil}

While manure application increased the diversity and abundance of ARGs and MGEs in the soil of the manure region, background soil was still a main source of the resistome and mobilome of the manured soil. Antibiotics are naturally occurring in soil, therefore indigenous soil bacteria harbor intrinsic resistome and mobilome. The indigenous bacterial population in the soil may hinder the establishment of the manureborne ARG-carrying bacteria in soil (Chen et al., 2017; Pérez-Valera et al., 2019), due partially to the antagonistic interactions between manure-borne microbes and indigenous soil microbes (Barrios et al., 2020). As a result, the background soil may serve as a significant source of the resistome and mobilome of the surface soil at the time of soil sample collection (i.e., one week after manure application).

The resistome and mobilome in the soil of the setback region were not affected by manure application. According to the beta diversity analyses, manure application did not significantly alter the resistome or mobilome of the soil in the setback region. These results suggest that even though ARG- and MGE-carrying manure particles in runoff may settle on surface soil within the setback region, it is not substantial enough to significantly change the resistome or mobilome in the soil several days following a rainfall event (Muirhead et al., 2006). This may be due to the diluted concentrations of manure-borne ARGs and MGEs in runoff (Xie et al., 2018b) and the limited settling of smaller manure particles from runoff (Muirhead et al., 2006).

In this study, surface soil samples were collected 7 days after manure application. Microcosm and field experiments demonstrate that onetime manure application can have transient impacts on the resistome of soil (Gou et al., 2018; Macedo et al., 2021). Temporary increases of ARG and MGE abundance in soil can result from direct addition of manure-borne ARGs and MGEs (Chen et al., 2017; Liu et al., 2021) as well as from indirect enrichment of indigenous ARG- and MGE-carrying soil bacteria due to manure-borne nutrients (Macedo et al., 2021). As manure bacteria may not thrive long-term within a soil environment, the ARG and MGE abundance in manured soil may gradually decrease and eventually return to a baseline condition. In addition to sampling time and setback distance, manure application methods can also affect the dissipation of ARGs and MGEs in soil. The broadcast manure application method used in this study is prone to causing loss of manure-borne bacteria to runoff (Joy et al., 2013), which could consequently result in the return of ARG and MGE levels in soil back to baseline levels (Barrios et al., 2020; Joy et al., 2013).

\section{Conclusions}

Simulated rainfall tests were conducted on field plots to examine the change of resistome and mobilome in runoff as a function of setback distance and to determine the attributions of manure and soil to the ARGs and MGEs in runoff following the land application of swine manure slurry. Manure application significantly increased the diversity and abundance of ARGs and MGEs in runoff. When setback distance increased to $\sim 40 \mathrm{~m}$, the SRA of ARGs and MGEs in runoff from the manure amended plots decreased to levels of ARGs and MGEs in runoff from control plots. As setback distance increased, the contribution of manure-borne ARGs and MGEs to the resistome and mobilome in runoff diminished, while that of soil-borne ARGs and MGEs became dominant. While manure application had significant impacts on the resistome and mobilome of the soil within the manure region, it had limited impacts on the soil in the setback region. This study improved our knowledge and understanding of the effects of setback distance as a BMP for antibiotic resistance control on cropland areas. It is recognized that the conclusions of the study were specific to the experimental conditions tested.

\section{CRediT authorship contribution statement}

Noelle Mware: Investigation, Methodology, Data curation, Visualization, Writing - original draft. Maria Hall: Investigation, Methodology. Selvakumar Rajendran: Investigation, Methodology. John Gilley: Investigation, Funding Acquisition. Writing - review \& editing. Amy Schmidt: Investigation, Funding Acquisition, Writing - review \& editing. Shannon Bartelt-Hunt: Funding Acquisition, Investigation. Yifan Zhang: Methodology. Xu Li: Conceptualization, Methodology, Writing - review \& editing, Supervision, Funding acquisition.

\section{Declaration of Competing Interest}

The authors declare that they have no known competing financial interests or personal relationships that could have appeared to influence the work reported in this paper.

\section{Acknowledgements}

The study was funded by the National Pork Board (\#16-072) and the US Department of Agriculture (\#2017-68003-26497). N.A.M. and M.C. $\mathrm{H}$ were partially supported by the Daugherty Water for Food Global Institute. S.K. was supported by the WARI program through the Daugherty Water for Food Global Institute and Indo-US Science and Technology Forum. The authors also thank Robert Stedtfeld for technical assistance.

\section{Novelty Statement}

The novelty of the work lies in three aspects. First, while livestock manure has been recognized as a source of antibiotic resistance genes (ARGs) to the environment, there has been few field studies to quantify the transport of manure-borne ARGs in agricultural runoff. We employed field plots and a rainfall simulator in this work. Second, instead of quantitative PCR, we employed high-throughput quantitative PCR (HT-qPCR) to study the entire resistome and mobilome of the runoff and soil samples. Third, the data from HT-qPCR was processed using a Bayesian model to distinguish manure-borne ARGs from background soil-borne ARGs. 


\section{Appendix A. Supporting information}

Supplementary data associated with this article can be found in the online version at doi:10.1016/j.jhazmat.2022.128278.

\section{References}

Al-wadaey, A., Wortmann, C., Shapiro, C., Franti, T., Eisenhauer, D., 2010. Manure application setback effect on phosphorus and sediment in runoff. J. Soil Sci. Environ. Manag. 1 (5), 92-98.

Baral, D., Dvorak, B.I., Admiraal, D., Jia, S., Zhang, C., Li, X., 2018a. Tracking the sources of antibiotic resistance genes in an urban stream during wet weather using shotgun metagenomic analyses. Environ. Sci. Technol. 52 (16), 9033-9044.

Baral, D., Speicher, A., Dvorak, B., Admiraal, D., Li, X., 2018b. Quantifying the relative contributions of environmental sources to the microbial community in an urban stream under dry and wet weather conditions. Appl. Environ. Microbiol. 84 (15).

Barrios, R.E., Khuntia, H.K., Bartelt-Hunt, S.L., Gilley, J.E., Schmidt, A.M., Snow, D.D., Li, X., 2020. Fate and transport of antibiotics and antibiotic resistance genes in runoff and soil as affected by the timing of swine manure slurry application. Sci. Total Environ. 712, 136505.

Bastian, M., Heymann, S., Jacomy, M., 2009. Gephi: an open source software for exploring and manipulating networks. Icwsm 8 (2009), 361-362.

Chen, Q.-L., An, X.-L., Li, H., Zhu, Y.-G., Su, J.-Q., Cui, L., 2017. Do manure-borne or indigenous soil microorganisms influence the spread of antibiotic resistance genes in manured soil? Soil Biol. Biochem. 114, 229-237.

Durso, L.M., Wedin, D.A., Gilley, J.E., Miller, D.N., Marx, D.B., 2016. Assessment of selected antibiotic resistances in ungrazed native Nebraska prairie soils. J. Environ. Qual. 45 (2), 454-462.

Ginting, D., Moncrief, J.F., Gupta, S.C., Evans, S.D., 1998. Corn Yield, Runoff, and Sediment Losses from Manure and Tillage Systems. Journal of Environmental Quality 27, 1396-1402.

Gou, M., Hu, H.-W., Zhang, Y.-J., Wang, J.-T., Hayden, H., Tang, Y.-Q., He, J.-Z., 2018 Aerobic composting reduces antibiotic resistance genes in cattle manure and the resistome dissemination in agricultural soils. Sci. Total Environ. 612, 1300-1310.

Grande, J.D., Karthikeyan, K., Miller, P.S., Powell, J.M., 2005. Residue level and manure application timing effects on runoff and sediment losses. Journal of Environmental Quality 34 (4), 1337-1346.

Hall, M.C., Mware, N.A., Gilley, J.E., Bartelt-Hunt, S.L., Snow, D.D., Schmidt, A.M., Eskridge, K.M., Li, X., 2020. Influence of setback distance on antibiotics and antibiotic resistance genes in runoff and soil following the land application of swine manure slurry. Environ. Sci. Technol. 54 (8), 4800-4809.

Henry, R., Schang, C., Coutts, S., Kolotelo, P., Prosser, T., Crosbie, N., Grant, T., Cottam, D., O'Brien, P., Deletic, A., McCarthy, D., 2016. Into the deep: Evaluation of SourceTracker for assessment of faecal contamination of coastal waters. Water Res. 93, 242-253.

Holger Heuer, H.Sa.K.S., 2011. Antibiotic resistance gene spread due to manure application on agricultural fields. Curr. Opin. Microbiol. 14 (3), 236-243.

Hu, H.-W., Wang, J.-T., Li, J., Shi, X.-Z., Ma, Y.-B., Chen, D., He, J.-Z., 2017. Long-term nickel contamination increases the occurrence of antibiotic resistance genes in agricultural soils. Environ. Sci. Technol. 51 (2), 790-800.

Jacobs, K., Wind, L., Krometis, L.A., Hession, W.C., Pruden, A., 2019. Fecal Indicator Bacteria and Antibiotic Resistance Genes in Storm Runoff from Dairy Manure and Compost-Amended Vegetable Plots. J. Environ. Qual. 48 (4), 1038-1046.

Joy, S.R., Bartelt-Hunt, S.L., Snow, D.D., Gilley, J.E., Woodbury, B.L., Parker, D.B., Marx, D.B., Li, X., 2013. Fate and transport of antimicrobials and antimicrobial resistance genes in soil and runoff following land application of swine manure slurry. Environ. Sci. Technol. 47 (21), 12081-12088.

Knights, D., Kuczynski, J., Charlson, E.S., Zaneveld, J., Mozer, M.C., Collman, R.G., Bushman, F.D., Knight, R., Kelley, S.T., 2011. Bayesian community-wide cultureindependent microbial source tracking. Nat. Methods 8 (9), 761-763.

Li, B., Yang, Y., Ma, L., Ju, F., Guo, F., Tiedje, J.M., Zhang, T., 2015. Metagenomic and network analysis reveal wide distribution and co-occurrence of environmental antibiotic resistance genes. ISME J. 9 (11), 2490-2502.

Li, J., Xin, Z., Zhang, Y., Chen, J., Yan, J., Li, H., Hu, H., 2017. Long-term manure application increased the levels of antibiotics and antibiotic resistance genes in a greenhouse soil. Appl. Soil Ecol. 121, 193-200.

Liu, W., Ling, N., Guo, J., Ruan, Y., Wang, M., Shen, Q., Guo, S., 2021. Dynamics of the antibiotic resistome in agricultural soils amended with different sources of animal manures over three consecutive years. J. Hazard. Mater. 401, 123399.

Macedo, G., van Veelen, H.P.J., Hernandez-Leal, L., van der Maas, P., Heederik, D., Mevius, D., Bossers, A., Schmitt, H., 2021. Targeted metagenomics reveals inferior resilience of farm soil resistome compared to soil microbiome after manure application. Sci. Total Environ. 770, 145399.

Mailapalli, D.R., Burger, M., Horwath, W.R., Wallender, W.W., 2013. Crop Residue Biomass Effects on Agricultural Runoff. Appl. Environ. Soil Sci. 2013, 805206.

Mei, X., Zhu, Q., Ma, L., Zhang, D., Wang, Y., Hao, W., 2018. Effect of stand origin and slope position on infiltration pattern and preferential flow on a Loess hillslope. Land Degrad. Dev. 29 (5), 1353-1365.

Meyers, M.A., Durso, L.M., Gilley, J.E., Miller, D.N., Li, X., Schmidt, A.M., 2020. Setback distance impacts on transport and antibiotic resistance phenotypes of fecal indicators. Agrosystems. Geosci. Environ. 3 (1), e20081.

Muirhead, R.W., Collins, R.P., Bremer, P.J., 2006. Interaction of Escherichia coli and soil particles in runoff. Appl. Environ. Microbiol. 72 (5), 3406-3411.

Newman, M.E., 2006. Modularity and community structure in networks. Proc. Natl. Acad. Sci. 103 (23), 8577-8582.

Oksanen, J., Blanchet, F.G.F., Michael, Kindt, R., Legendre, P., McGlinn, D., Minchin, P. R., O'Hara, R.B., Simpson, G.L., Solymos, P., H. Stevens, M.H., Szoecs, E., Wagner, H., 2019. vegan: Community Ecology Package. R. Package Version 2, 5. 〈htt ps://CRAN.R-project.org/package=vegan $\rangle$.

Oun, A., Kumar, A., Harrigan, T., Angelakis, A., Xagoraraki, I., 2014. Effects of biosolids and manure application on microbial water quality in rural areas in the US. Water 6 (12), 3701-3723.

Pennsylvania Department of Environmental Protection (2011) Land Application of Manure - A Supplement to Manure Management for Environmental Protection.

Pérez-Valera, E., Kyselková, M., Ahmed, E., Sladecek, F.X.J., Goberna, M., Elhottová, D., 2019. Native soil microorganisms hinder the soil enrichment with antibiotic resistance genes following manure applications. Sci. Rep. 9 (1).

Pruden, A., Arabi, M., Storteboom, H.N., 2012. Correlation between upstream human activities and riverine antibiotic resistance genes. Environ. Sci. Technol. 46 (21), 11541-11549.

Revelle, W.R. (2017) psych: Procedures for personality and psychological research.

Roodsari, R., Shelton, D., Shirmohammadi, A., Pachepsky, Y., Sadeghi, A., Starr, J., 2005. Fecal coliform transport as affected by surface condition. Trans. ASAE 48 (3), 1055-1061.

Soni, B., Bartelt-Hunt, S.L., Snow, D.D., Gilley, J.E., Woodbury, B.L., Marx, D.B., Li, X., 2015. Narrow grass hedges reduce tylosin and associated antimicrobial resistance genes in agricultural runoff. J. Environ. Qual. 44 (3), 895-902.

Staley, C., Kaiser, T., Lobos, A., Ahmed, W., Harwood, V.J., Brown, C.M., Sadowsky, M. J., 2018. Application of SourceTracker for Accurate Identification of Fecal Pollution in Recreational Freshwater: A Double-Blinded Study. Environ. Sci. Technol. 52 (7), 4207-4217.

Staley, Z.R., Schmidt, A.M., Woodbury, B., Eskridge, K.M., Durso, L., Li, X., 2020. Corn stalk residue may add antibiotic-resistant bacteria to manure composting piles. J. Environ. Qual. 49 (3), 745-753.

Stedtfeld, R.D., Guo, X., Stedtfeld, T.M., Sheng, H., Williams, M.R., Hauschild, K., Gunturu, S., Tift, L., Wang, F., Howe, A., 2018. Primer set 2.0 for highly parallel qPCR array targeting antibiotic resistance genes and mobile genetic elements. FEMS Microbiol. Ecol. 94 (9), fiy130.

Su, J.Q., Wei, B., Xu, C.Y., Qiao, M., Zhu, Y.G., 2014. Functional metagenomic characterization of antibiotic resistance genes in agricultural soils from China. Environ. Int. 65, 9-15.

Wang, F.-H., Qiao, M., Su, J.-Q., Chen, Z., Zhou, X., Zhu, Y.-G., 2014. High Throughput Profiling of Antibiotic Resistance Genes in Urban Park Soils with Reclaimed Water Irrigation. Environ. Sci. Technol. 48 (16), 9079-9085.

Wickham, H., 2016. ggplot2: elegant graphics for data analysis. springer,

Xie, W.-Y., Yuan, S.-T., Xu, M.-G., Yang, X.-P., Shen, Q.-R., Zhang, W.-W., Su, J.-Q. Zhao, F.-J., 2018a. Long-term effects of manure and chemical fertilizers on soil antibiotic resistome. Soil Biol. Biochem. 122, 111-119.

Xie, W.Y., Shen, Q., Zhao, F., 2018b. Antibiotics and antibiotic resistance from animal manures to soil: a review. Eur. J. Soil Sci. 69 (1), 181-195.

Zhang, Y.-J., Hu, H.-W., Gou, M., Wang, J.-T., Chen, D., He, J.-Z., 2017. Temporal succession of soil antibiotic resistance genes following application of swine, cattle and poultry manures spiked with or without antibiotics. Environ. Pollut. 231, 1621-1632.

Zhao, F., Chen, L., Yang, L., Sun, L., Li, S., Li, M., Feng, Q., 2020. Effects of land use and rainfall on sequestration of veterinary antibiotics in soils at the hillslope scale. Environ. Pollut. 260, 114112.

Zhu, Y.-G., Johnson, T.A., Su, J.-Q., Qiao, M., Guo, G.-X., Stedtfeld, R.D., Hashsham, S.A., Tiedje, J.M., 2013. Diverse and abundant antibiotic resistance genes in Chinese swine farms. Proc. Natl. Acad. Sci. 110 (9), 3435-3440.

Zhu, Y.-G., Zhao, Y., Li, B., Huang, C.-L., Zhang, S.-Y., Yu, S., Chen, Y.-S., Zhang, T., Gillings, M.R., Su, J.-Q., 2017. Continental-scale pollution of estuaries with antibiotic resistance genes. Nat. Microbiol. 2 (4), 16270. 